\title{
Risk of anaemia among women engaged in biomass-based fish smoking as their primary livelihood in the central region of Ghana: a comparative cross-sectional study
}

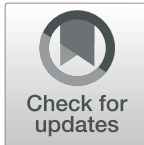

Daniel Armo-Annor ${ }^{1}$, Esi K. Colecraft ${ }^{1 *}$ (D) Seth Adu-Afarwuah ${ }^{1}$, Aaron Kobina Christian ${ }^{2}$ and Andrew D. Jones ${ }^{3}$

\begin{abstract}
Background: Fish smoking using biomass fuel is an important livelihood for women living in the coastal regions of Ghana and may contribute to anaemia risk. We assessed whether women who smoke fish as their primary livelihood are at increased risk of anaemia compared to women in other livelihoods in the Central Region of Ghana.

Methods: We conducted a comparative cross-sectional study of 330 randomly selected adult women (18-49 years) whose primary livelihood was either fish smoking (FSL) involving the burning of biomass fuel $(n=175)$ or other livelihoods $(\mathrm{OL})$ not involving burning of firewood $(n=155)$. Data on participants' recent diet were collected from a single, quantitative 24-h dietary recall and qualitative 7-day food frequency questionnaire of animal-source food (ASF) consumption. We further assessed participants' haemoglobin concentration using the Urit 12 Hemocue system. We compared total iron intakes, the proportion of dietary iron from animal and plant sources, mean haemoglobin concentrations, and anaemia prevalence between FSL and OL women.

Results: Fish was the most frequently consumed ASF by both groups of women. Although OL women consumed more diverse ASFs in the past week compared with the FSL women (3.4 $\pm 1.2 \mathrm{vs.} 2.7 \pm 1.3 ; p<0.001)$, the contribution of ASFs to total iron intake in the past day was greater for the FSL women (49.5\% vs. 44.0\%; $p=0.030$ ). Estimated total dietary iron intake in the past day was generally low $(5.2 \pm 4.7 \mathrm{mg})$ and did not differ by group. The unadjusted prevalence of anaemia was 32 and $27.1 \%$ among the FSL and OL women, respectively $(p=0.33)$. After covariates adjustment, the FSL women had statistically higher anaemia prevalence (36.4\% vs. $20.5 \% ; p=0.032)$ and $80 \%$ greater risk of being anemic (RR: 1.8; $95 \%$ Cl: 1.1, 3.0) than the OL women.

Conclusion: Women who use biomass fuel to smoke fish as their primary livelihood had an increased risk of anaemia. Furthermore, the average 24-h dietary iron intake among both the FSL and OL women was below their daily iron requirement. Interventions to enhance women's dietary iron intake and reduce their livelihood related biomass smoke exposure may be warranted in this population.
\end{abstract}

Keywords: Anaemia, Fish smoking, Livelihood, Biomass fuel, Ghana

\footnotetext{
* Correspondence: ekcolecraft@ug.edu.gh

'Department of Nutrition and Food Science, University of Ghana, P.O. Box LG

134, Accra, Ghana

Full list of author information is available at the end of the article
}

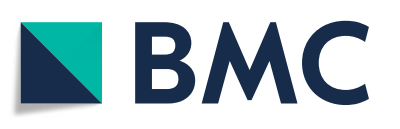

(- The Author(s). 2021 Open Access This article is licensed under a Creative Commons Attribution 4.0 International License, which permits use, sharing, adaptation, distribution and reproduction in any medium or format, as long as you give appropriate credit to the original author(s) and the source, provide a link to the Creative Commons licence, and indicate if changes were made. The images or other third party material in this article are included in the article's Creative Commons licence, unless indicated otherwise in a credit line to the material. If material is not included in the article's Creative Commons licence and your intended use is not permitted by statutory regulation or exceeds the permitted use, you will need to obtain permission directly from the copyright holder. To view a copy of this licence, visit http://creativecommons.org/licenses/by/4.0/. The Creative Commons Public Domain Dedication waiver (http://creativecommons.org/publicdomain/zero/1.0/) applies to the data made available in this article, unless otherwise stated in a credit line to the data. 


\section{Background}

Anaemia prevalence among Ghanaian women of reproductive age (WRA) remains unacceptably high at $42 \%$ [1]. Anaemia has multiple etiologies including iron deficiency due primarily to suboptimal dietary iron intake, infections, worm infestations, and inherited blood disorders [2, 3]. The relative contribution of the various causes to the total burden of anaemia varies by region, population group and environmental factors [3]. According to the World Health Organization [4], about $50 \%$ of all anaemia is due to iron deficiency associated primarily with inadequate iron intake. However, in a systematic analysis of national surveys, the authors reported that countries with very high burden of inflammation (determined by an index derived from infection, hygiene, and/or overnutrition indicators) had the lowest prevalence of anaemia among WRA [5]. Furthermore, anaemia attributable to iron deficiency among WRA was considerably lower (about 16\%) for countries with a severe public health burden of anaemia (i.e. prevalence greater than $40 \%$ ) [5].

Smoke from burning biomass fuel is another source of inflammation which has also been implicated as a possible cause of anaemia in a few studies with children and women. Anaemia associated with biomass smoke is believed to stem from altered haemoglobin metabolism and disruption of red bloods cells resulting from systemic inflammation and oxidative stress respectively, induced by pollutants in the smoke [6-9]. Kyu et al. [10] conducted a multilevel analysis of data from Demographic and Health Surveys for 29 countries and found that country-level exposures to biofuel smoke were associated with up to a four-fold increased odds of anaemia among children under five years of age [10]. Using data from the 1998-1999 National Family Health Survey in India, Mishra \& Retherford [11] reported a significantly higher risk of moderate-to-severe anaemia among preschool-aged children living in households where biofuels were used for cooking compared to those in households using cleaner fuels [11]. However, Machisa et al. [12] did not find a significant association between household use of biomass fuel and anaemia among preschoolaged children in Swaziland [12]. In India, pregnant women in the Nagpur district whose main source of fuel for cooking was biomass-based (i.e., wood, straw/shrubs/ grass, agricultural crop, or animal dung) had a higher adjusted relative risk of both mild and moderate-tosevere anaemia [13]. Similarly, Sukhsohale et al. [14] found that among non-pregnant women from the same Indian district, those with the highest biomass smoke exposure index were significantly more likely to have anaemia [14]. In contrast, blood haemoglobin concentration did not differ between non-pregnant Guatemalan women who cooked with biomass-based smoke ovens versus those who used a smokeless stove [15].
Preserving fish using smoke (most commonly from burning wood) is widespread among approximately 185 fishing villages along Ghana's coast and inland fishing communities where women make up about $70 \%$ of the workforce in the post-harvest fisheries value chain [16]. Indeed, fish smoking using firewood is the main livelihood of the majority of Ghanaian women living in coastal communities. Depending on the species and desired dryness, fish may be smoked for 2 to $18 \mathrm{~h}$ using smoking ovens that emit considerable amounts of smoke [17]. Thus, it is probable that being engaged in fish smoking as a livelihood may expose women to chronic smoke inhalation during the fish smoking process which may increase their risk of anaemia [18]. Furthermore, women who smoke fish as their primary livelihood may consume less diverse animal-source foods (ASF) because of greater dependence on fish and so limit their intake of comparatively richer sources of iron such as livestock meats. Kawarazuka and Bene [19] observed that due to variability in the iron content of different fish species, heavy dependence on fish at the expense of other ASFs may influence dietary iron intakes and predispose women to iron deficiency anaemia.

The Central Region of Ghana, the site of this study, is among the regions of Ghana with the highest prevalence of anaemia, and a large proportion of women in the area derive their livelihoods from fish smoking activities $[1$, 17]. It is unclear the extent to which women fish smokers consume fish and/or other ASFs and whether these women have a greater risk of anaemia. The aims of this comparative cross-sectional study were to compare among women whose primary livelihood is fish smoking and those engaged in other livelihoods not involving the burning of firewood: i) mean haemoglobin concentration and prevalence of anaemia, and ii) animal-source food intakes and their contribution to total iron intakes. We hypothesized that women engaged in fish smoking as their primary livelihood would have a greater risk of anaemia possibly due to higher smoke exposure and/or consumption of less diverse ASFs.

Findings from this study will add to the body of evidence on the association between biomass fuel use and anaemia among WRA and delineate whether there are unique considerations needed in efforts to address anaemia in WRA whose primary livelihoods expose them to chronic biomass smoke inhalation.

\section{Methods}

\section{Study design, setting and participants}

This comparative cross-sectional study was carried out in Biriwa, a fishing community of 7086 people in the Mfantseman Municipality of the Central Region of Ghana [20]. Given its relatively large size, Biriwa was purposively selected from six fishing villages that were 
part of a larger pilot study conducted in the Central Region (the Invisible Fishers study) from May 2018 to $\mathrm{Au}$ gust 2019 examining the impacts of various fisheries value chain and other behavior change interventions on anaemia among women of reproductive age (WRA) [21].

The inclusion criteria for participation in the study were, being an adult non-pregnant non-lactating WRA (18 to 49 years), living in Biriwa and being willing to participate in the study. A screening census was completed to list all adult women in the community according to their primary livelihood for the past two years; whether fish smoking involving burning of firewood (FSL women) or other livelihoods not involving burning of firewood and living in a household where no one smokes fish as a major economic activity (OL women). Due to concern about not achieving the estimated sample size, no restrictions were placed on the number of women who could be listed per household during the census. A total of 355 eligible FSL and OL women in 311 households were listed. Women participating in the Invisible Fishers study in Biriwa $(N=10)$ were ineligible to participate in this study. A sample size of 175 participants per group (i.e., FSL and OL) was estimated based on a $5 \%$ level of significance, $80 \%$ power, expected anaemia prevalence of $50 \%$ (using baseline anaemia prevalence for the Central Region from the Invisible Fishers study) and 35\% (using prevalence of anaemia in the Upper West Region of Ghana) where fish smoking is expected to be only minimally practiced [1] among the FSL women and OL women, respectively, and 3\% contingency to cater for incomplete surveys. As 194 eligible FSL women were listed from the census, we randomly selected 175 to participate in the study using the RAND function in excel. About 30\% $(n=52)$ where from the same households (two or three [two instances] women from the same household). The remaining 19 eligible women were put on a waiting list and replaced women who could not complete the study due to reasons such as refusals, travel and relocation. The number of eligible OL women listed $(n=161)$ was lower than the estimated sample size so all of them were invited to participate in the study. About 19\% $(n=30)$ where from the same household (two or three [one instance] from the same household).

\section{Data collection and measurement of variables}

Data collection took place from December 2018 to February 2019 and was completed with semi-structured questionnaires. Questionnaires were designed using the Kobotoolbox platform and loaded on Android tablets using the Open Data Kit (ODK) for data collection. Three research assistants with at least high school education were recruited and trained by the primary researcher to support the data collection activities. The questionnaire was pre-tested on women with similar characteristics in a neighboring community before it was administered to the actual study respondents. Face-toface interviews were completed with participants in their preferred local language (Fante or Twi) or English at their homes or workplaces. Data were recorded with Android tablets by direct electronic data entry using the ODK.

The research assistants obtained information on household characteristics, as well as personal social demographic characteristics, reproductive history, health, recent diet and use of firewood from the selected participant in each household (see Additional file 1). Using the Urit12 HemoCue (URIT Medical Electronics Co., LTD, China) system, a lancet was used to prick the forefinger of each participant and a drop of blood was gently squeezed onto the sampling point of the system to obtain a digital reading of the haemoglobin concentration in the sample. Anaemia was defined as having haemoglobin concentration of less than $12 \mathrm{~g} / \mathrm{dl}$ [22] based on one sample per participant. A one day 24-h recall method was used to record all foods and beverages (except water) consumed by the study participant in the past 24h [23]. Wooden food models and household measures were used to help participants estimate quantities consumed. The frequency of consumption of different ASFs by the participant in the past week was captured with an abbreviated food frequency questionnaire listing seven categories of commonly consumed ASFs including fish and seafood, milk and milk products, livestock meats, eggs, poultry, organ meats and bush meats (see Additional file 1). This was a semiquantitative questionnaire which required participants to specify the number of days in the past week they ate a particular ASF without specifying the portion size. From the 24-h recall data, we determined each participant's dietary diversity score based on the 10 food groups used to compute the FAO's Minimum Dietary Diversity for Women indicator [24] and computed recent total iron intakes for participants. The iron content of foods consumed in the past 24-h was determined using a food database (RIING food composition database, Nutrition Department, University of Ghana, unpublished). We estimated the bioavailability of the iron from the foods consumed using a previously published method [25]. For each eating event, $40 \%$ of the iron content of meat, fish and poultry (MFP) consumed was considered as heme iron and available and the remaining $60 \%$ non-heme while $100 \%$ of iron from non-animal sources consumed was considered non-heme. Bioavailability of non-heme iron was computed as $5,10 \%$ or $15 \%$ of the total iron content of the food source depending on the quantities of MFP and vitamin $\mathrm{C}$ consumed in the same eating event or meal [25]. The proportion of the total estimated 
bioavailable iron intake from all foods contributed by ASFs consumed in the 24-h recall period was computed. Additionally, we calculated ASF diversity as the number of different categories of ASF (out of a total of seven) consumed by the participant in the past seven days. Completed questionnaires were reviewed for completeness at the end of each day. Participants with missing or incomplete responses were contacted the following day to complete the missing information.

\section{Data analysis}

Data were managed, cleaned and analyzed using the Statistical Software Package for Social Sciences (SPSS) version 22.0 (Chicago, USA) and SAS for Windows Release 9.4 (Cary, NC, USA). One duplicate record was identified and removed during data cleaning, otherwise all completed questionnaires were included in the analysis. Bivariate analyses using Student's T-tests for continuous variables and Chi-Square tests for categorical variables were used to summarize differences in background and household characteristics of the FSL and OL women. Additionally, we compared group differences in mean ASF diversity (number of different ASFs consumed in the past seven days), total iron intakes, and mean percent contribution of ASFs to total iron intakes in the past 24-h.

Blood haemoglobin concentrations were compared between the two groups of women using a general linear model and ANCOVA for unadjusted and adjusted comparisons, respectively. The SAS PROC GLIMMIX procedure was used in both cases. Unadjusted and adjusted means with their 95\% CIs were calculated. Anaemia prevalence was compared using a simple logistic regression model for an unadjusted comparison, and multiple logistic regression model for an adjusted comparison. The SAS PROC GLIMMIX procedure was used in both cases. A binary distribution and log-link function were specified in the SAS procedures so that relative risks between groups and their 95\% CIs were calculated. Covariates for the ANCOVA and logistic regression models were selected by correlating anaemia with each covariate so that only those independent variables significantly associated with the outcome at alpha $=0.2$ [26] were selected for the multiple logistic regression model. This conservative level of alpha was chosen to minimize the risk of type II error in variable selection [27]. In addition to covariates selected through correlation analysis (i.e., marital status, fever in the past two weeks, fish smoking livelihood, dewormed in past 3 months, ever been pregnant and age), other covariates including number of days spent smoking fish, fuel for cooking, ASF diversity, and access to a toilet facility were selected for the final ANCOVA and multiple logistic regression models if they were associated with haemoglobin concentration or anaemia, respectively.

\section{Results \\ Background and household characteristics of women}

A total of 355 women were invited to participate in the study and 330 (93\%) of them completed the survey. Out of the $25(7 \%)$ who did not participate, $12(48 \%)$ refused to participate $(\mathrm{FSL}$ women $=10$, OL women $=2), 11$ (44\%) were traveling out of the study area at the time of the survey (FSL women $=7$, OL women $=4)$ and $2(8 \%)$ FSL women could not be located on the scheduled day or after two additional attempts to interview them. Of the 330 women who completed the study, 175 (53\%) were FSL women and 155 (47\%) were OL women. The OL women were largely engaged in occupations such as hairdressing, dressmaking, petty trading, fish mongering, farming, and cleaning services as their primary livelihoods, with $<1 \%$ employed in professional (nursing and teaching) occupations. The FSL women smoked fish on average $4.9 \pm 1.3$ times a week for a mean of $3.9 \pm 1.7 \mathrm{~h}$ per day. With the dominance of fish smoking in the community $59 \%(n=95)$ of the OL women indicated that they occasionally assisted relatives or neighbours with fish smoking for an average of less than twice per week. Only two OL women reported having the sickle cell trait.

Background characteristics of the two groups of women in the study are summarized in Table 1. Compared to OL women, the FSL women were on average older ( 38 vs 29 years; $p<0.001$ ), more likely to be married $(82 \%$ vs. $57 \%$; $\mathrm{p}<0.001)$ and to have no formal education $(88 \%$ vs. $50 \% ; \mathrm{p}<0.001)$. The FSL women also had smoked fish as their primary livelihood for twice the number of years that the OL women had spent in their primary livelihoods. The OL women were less likely than the FSL women to have a supplementary income source and significantly more of them reported that they earned less than 500 Ghana Cedis (about 100 US dollars) per month. There were no group differences in the proportion of women who had taken deworming medication or an iron supplement in the past three or six months, respectively. The FSL women were more likely to report usually sleeping under a mosquito net. There were no group differences in the use of firewood for cooking or in living with someone who smokes cigarettes in the household.

\section{Recent diet, animal-source food diversity and iron intakes among women}

Starchy staples (including grains, white roots and tubers, and plantains) were consumed by almost all the women in the past day and at least $89 \%$ of women consumed meat, poultry, and fish in the past day (Fig. 1). Less than 
Table 1 Background characteristics of women in fish smoking livelihoods (FSL) or other livelihoods (OL) in the study

\begin{tabular}{|c|c|c|c|}
\hline Characteristic & $\begin{array}{l}\text { FSL women } \\
(n=175)\end{array}$ & $\begin{array}{l}\text { OL women } \\
(n=155)\end{array}$ & ${ }^{\text {ap}}$-value \\
\hline Age, years & $38 \pm 8^{b}$ & $29 \pm 8$ & $<0.001$ \\
\hline Married & $143(82)^{c}$ & $89(57)$ & $<0.001$ \\
\hline No Formal education & $87(50)$ & $18(12)$ & $<0.001$ \\
\hline Years in primary occupation & $12 \pm 7$ & $6 \pm 5$ & $<0.001$ \\
\hline Has supplementary income source & $78(45)$ & $45(29)$ & $<0.001$ \\
\hline Average monthly income $<\mathrm{GH} \subset 500^{d}$ & $103(59)$ & $130(84)$ & $<0.001$ \\
\hline Has been pregnant before & $170(97)$ & $107(69)$ & $<0.001$ \\
\hline Parity & $5 \pm 3$ & $2 \pm 2$ & $<0.001$ \\
\hline Dewormed in past 3 months & $47^{c}(27)$ & $47(30)$ & 0.50 \\
\hline Used iron supplements in past 6 months & $25(14)$ & $27(17)$ & 0.44 \\
\hline Usually sleeps under mosquito net & $106(61)$ & $72(47)$ & $<0.001$ \\
\hline Had fever in past 2 weeks & $47(27)$ & $29(19)$ & 0.08 \\
\hline Household size & $6 \pm 3$ & $5 \pm 3$ & $<0.001$ \\
\hline Household has improved toilet facility & $44(25)$ & $36(41)$ & $<0.001$ \\
\hline Use firewood as main fuel for cooking & $28(16)$ & $17(11)$ & 0.18 \\
\hline Cigarette smoker in household & $9(5)$ & $5(3)$ & 0.39 \\
\hline
\end{tabular}

${ }^{a}$ Significance associated with independent T-test for continuous variables, and chi-squared statistic for categorical variables ${ }^{b}$ Mean $\pm S D ;{ }^{c} n(\%) ;{ }^{d}$ exchange rate at time of the study I USD $=5 \mathrm{GHC}$

$50 \%$ of women in both groups consumed foods from the other eight food groupings. Consumption prevalence for the different food groups was similar in the two groups of women except for nuts and seeds where consumption prevalence was significantly higher among FSL women and significantly more OL women consumed foods from the dairy and pulses food groups. In the past day, the total iron intake for both groups of women from both plant and animal sources was about $5 \mathrm{mg}$ (Table 2). Mean percent contribution of iron from ASFs was, however, significantly higher for the FSL women $(49.5 \%$ vs. $44.0 \% ; p=0.030$ ). Differences in the types of ASFs consumed by the women in the past week are depicted in Fig. 2. Fish and seafood were the predominant ASF consumed by both groups of women in the past week. Less than $50 \%$ of FSL women consumed other types of ASF in the past week, whereas at least $60 \%$ of the OL women consumed foods made with dairy, livestock meats and eggs in the past week in addition to consuming foods from the fish and seafood group. Consumption

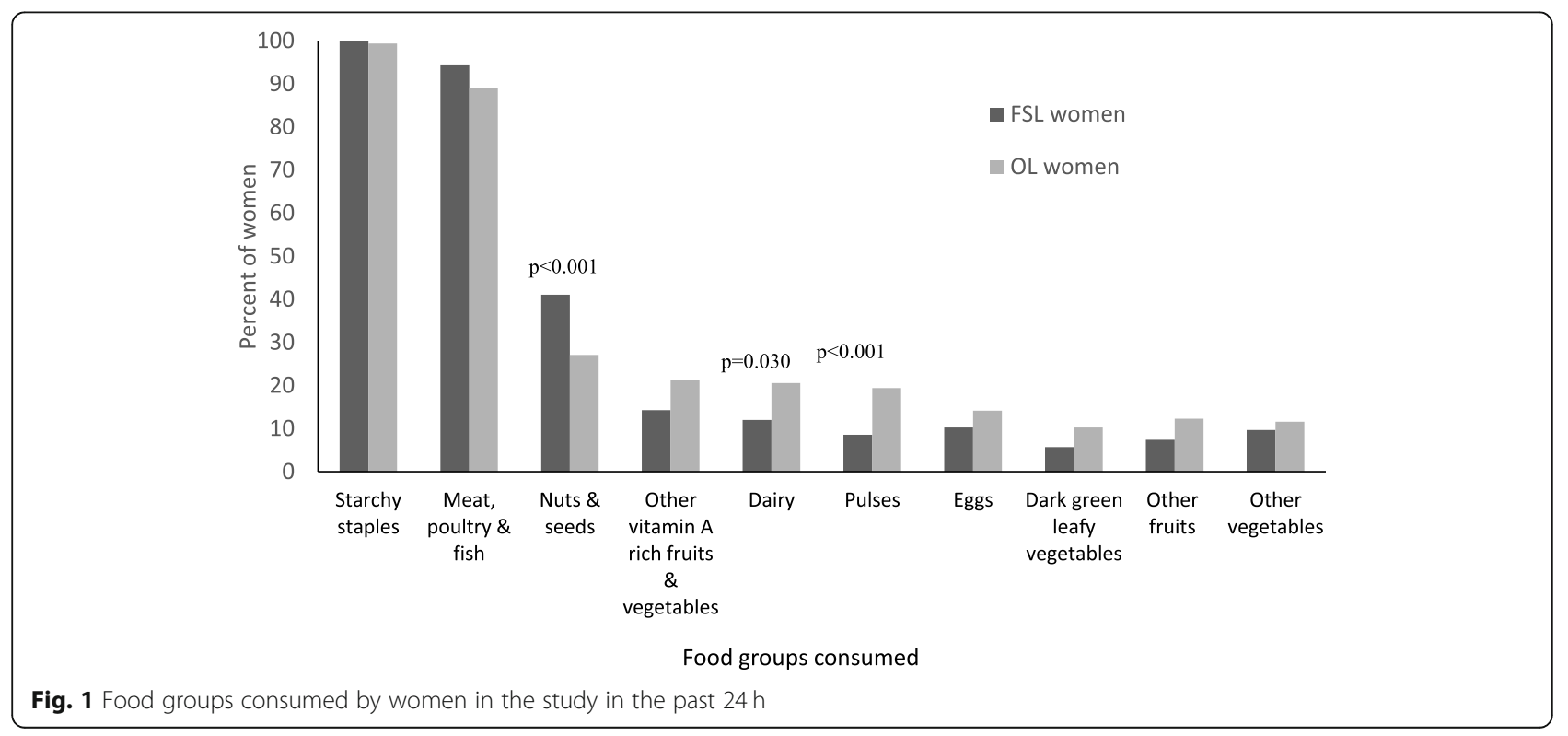


Table 2 Quantities of Animal Source Foods (ASF), total iron intake and contribution of ASF to total iron intakes in the past day

\begin{tabular}{|c|c|c|c|c|}
\hline Variable & $\begin{array}{l}{ }^{\mathrm{a}} \mathrm{FSL} \text { women } \\
(\mathrm{n}=175)\end{array}$ & $\begin{array}{l}{ }^{b} \mathrm{OL} \text { women } \\
(\mathrm{n}=155)\end{array}$ & Mann-Whitney U & ${ }^{\mathrm{C} P \text {-value }}$ \\
\hline Fish and shell fishes (g) & $90.8^{d}$ & 78.0 & $10,077.5$ & 0.68 \\
\hline Livestock meat (g) & 11.0 & 19.0 & 404.0 & 0.15 \\
\hline Milk and milk products (g) & 30.0 & 32.0 & 376.0 & 0.67 \\
\hline Eggs (g) & 124.4 & 100.0 & 172.0 & 0.15 \\
\hline Poultry (g) & 78.0 & 78.0 & 110.5 & 0.88 \\
\hline Total iron intake from all sources (mg) & $5.3 \pm 5.2^{\mathrm{e}}$ & $5.0 \pm 4.2$ & - & 0.57 \\
\hline Mean percent contribution of iron from ASF & $49.5 \pm 22.2$ & $44.0 \pm 23.9$ & - & 0.030 \\
\hline
\end{tabular}

${ }^{\mathrm{a}} \mathrm{FSL}=$ Fish Smoking Livelihood ${ }^{\mathrm{b}} \mathrm{OL}=$ Other Livelihood ${ }^{\mathrm{C}} \mathrm{P}$-value associated with Mann-Whitney $\mathrm{U}$ test or independent T-test, ${ }^{\mathrm{d}}$ Median, ${ }^{\mathrm{e}}$ Mean $\pm \mathrm{SD}$

of poultry and organ meats was also higher among OL women. Organ meats and bush meats (game) were only minimally consumed. Mean ASF diversity was significantly higher among the OL women $(3.4 \pm 1.2$ vs. $2.7 \pm$ 1.3; $p<0.001)$. However, with the exception of fish and seafood where the mean frequency of consumption in the last week was at least 12 times, the mean frequency of consuming the other ASF groups averaged about two or fewer times in the past week (Table 3).

\section{Unadjusted and adjusted differences in haemoglobin concentration and anaemia prevalence between FSL women and $\mathrm{OL}$ women}

In unadjusted analyses, mean \pm SD haemoglobin concentration did not differ between the two groups of women (FSL, $12.3 \pm 1.9 \mathrm{~g} / \mathrm{dl}$; OL, $12.6 \pm 1.8 \mathrm{~g} / \mathrm{dl} ; p=0.17$ ). About one-third of all the study women had mild (13.6\%), moderate $(13 \%)$ or severe (3\%) anaemia (Fig. 3) and there was no group difference in the prevalence of any anaemia among the women (FSL, 32\%; OL, 27\%; $p=$
0.33). After controlling for covariates, livelihood type was associated with haemoglobin concentration and the prevalence of anaemia. That is, the FSL women had significantly lower mean \pm SD haemoglobin concentration $(12.2 \pm 0.2 \mathrm{~g} / \mathrm{dl}$ vs. $12.8 \pm 0.2 \mathrm{~g} / \mathrm{dl} ; p=0.018)$ (Table 4$)$, and higher prevalence of anaemia (36.4\% vs. $20.5 \%$; $p=$ 0.032 ) than the OL women. The risk of anaemia was $80 \%$ greater in the FSL women compared with the OL women (Table 5).

\section{Discussion}

The study examined whether being engaged in fish smoking as a primary livelihood is associated with a higher risk of having anaemia among Ghanaian women compared to being engaged in a primary livelihood that does not involve burning of biomass smoke. Regardless of livelihood type, anaemia prevalence among women in the study was high although lower than the national average for rural communities (43\%) and for the Central Region of Ghana (48\%) [1]. The results show that

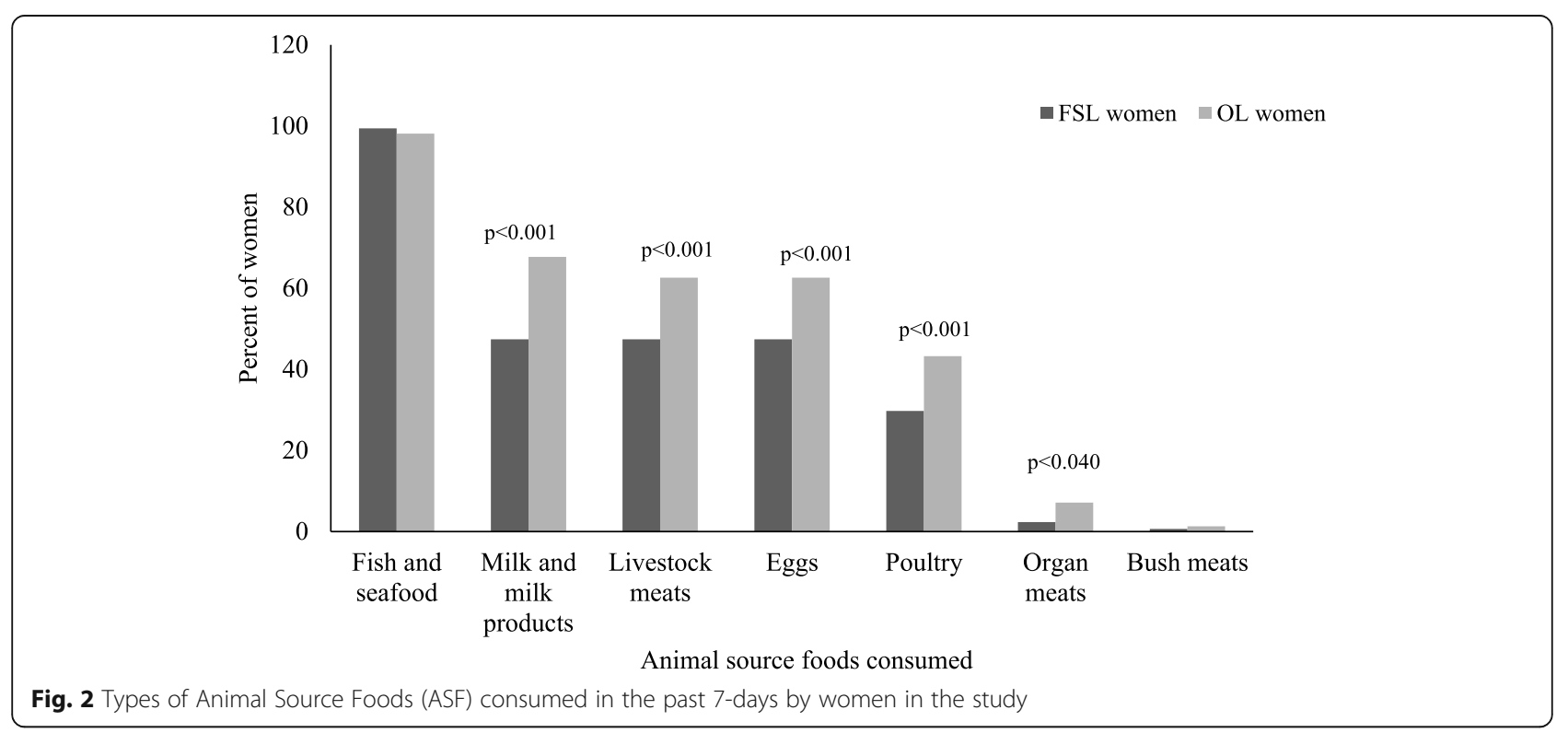


Table 3 Differences in mean \pm SD frequency of consuming different Animal Source Foods (ASF) in the past week

\begin{tabular}{llll}
\hline ASF group & FSL $^{\mathbf{a}}$ women $(\mathbf{n}=\mathbf{1 7 5})$ & $\mathbf{O L}^{\mathbf{b}}$ women $(\mathbf{n}=\mathbf{1 5 5})$ & $\mathbf{c}$-value \\
\hline Fish and seafood & $14.2 \pm 3.8$ & $12.4 \pm 4.7$ & $<0.001$ \\
Milk and milk products & $1.2 \pm 2.2$ & $1.9 \pm 2.1$ & $<0.001$ \\
Livestock meats & $1.1 \pm 1.5$ & $1.3 \pm 1.6$ & 0.09 \\
Eggs & $0.9 \pm 1.4$ & $1.2 \pm 1.4$ & 0.09 \\
Poultry & $0.5 \pm 0.9$ & $0.9 \pm 1.5$ & $<0.001$ \\
Organ meats & $<0.1 \pm 0.2$ & $0.1 \pm 0.3$ & 0.09 \\
Bush meats & $<0.1 \pm 0.1$ & $0.1 \pm 0.2$ & 0.36 \\
\hline
\end{tabular}

aish Smoking Livelihood ${ }^{\mathrm{b}}$ Other Livelihoods ${ }^{\mathrm{c}} \mathrm{P}$-value associated independent T-test

women who burn biomass fuel to smoke fish as their primary livelihood had lower blood haemoglobin concentrations and a higher burden of anaemia than those whose primary livelihoods did not involve burning of biofuels. Our findings corroborate those from several previous epidemiological studies that have reported an association between use of biomass fuel and increased likelihood of anaemia among preschool-aged children and women $[10,11,13,14,28]$. The biological mechanisms by which exposure to biomass fuel lead to lower haemoglobin concentrations and higher anaemia risk are believed to involve cytokine-mediated inflammation in response to pollutants in biomass smoke such as carbon monoxide, transition metals, and particulate matter less than $10 \mu \mathrm{m}\left(\mathrm{PM}_{10}\right)$ and less than $2.5 \mu \mathrm{m}\left(\mathrm{PM}_{2.5}\right)$ in diameter [13, 29]. Anaemia caused by systemic inflammation impairs iron homeostasis and red blood cell synthesis leading to low serum iron levels similar to iron- deficiency anaemia, but unlike iron-deficiency, does not depress iron stores [30].

In previous studies linking anaemia with smoke exposure, the source of smoke exposure was household use of biomass fuel for cooking indoors. However, in the present study the prevalence of using biomass fuel for household cooking was similar for the two groups of women and was not significantly associated with anaemia prevalence. In the study community, fish smoking is largely done outdoors although some of the women smoked fish in semi-enclosed structures. Our results suggest that exposure to outdoor smoke from fish smoking among the FSL women might have had a similar impact on haemoglobin concentration and anaemia prevalence as did exposure to indoor biomass fuel in those previous studies. In fact outdoor exposure has also been shown to be associated with anaemia in children. For example, Morales-Ancajima et al. [31], observed that

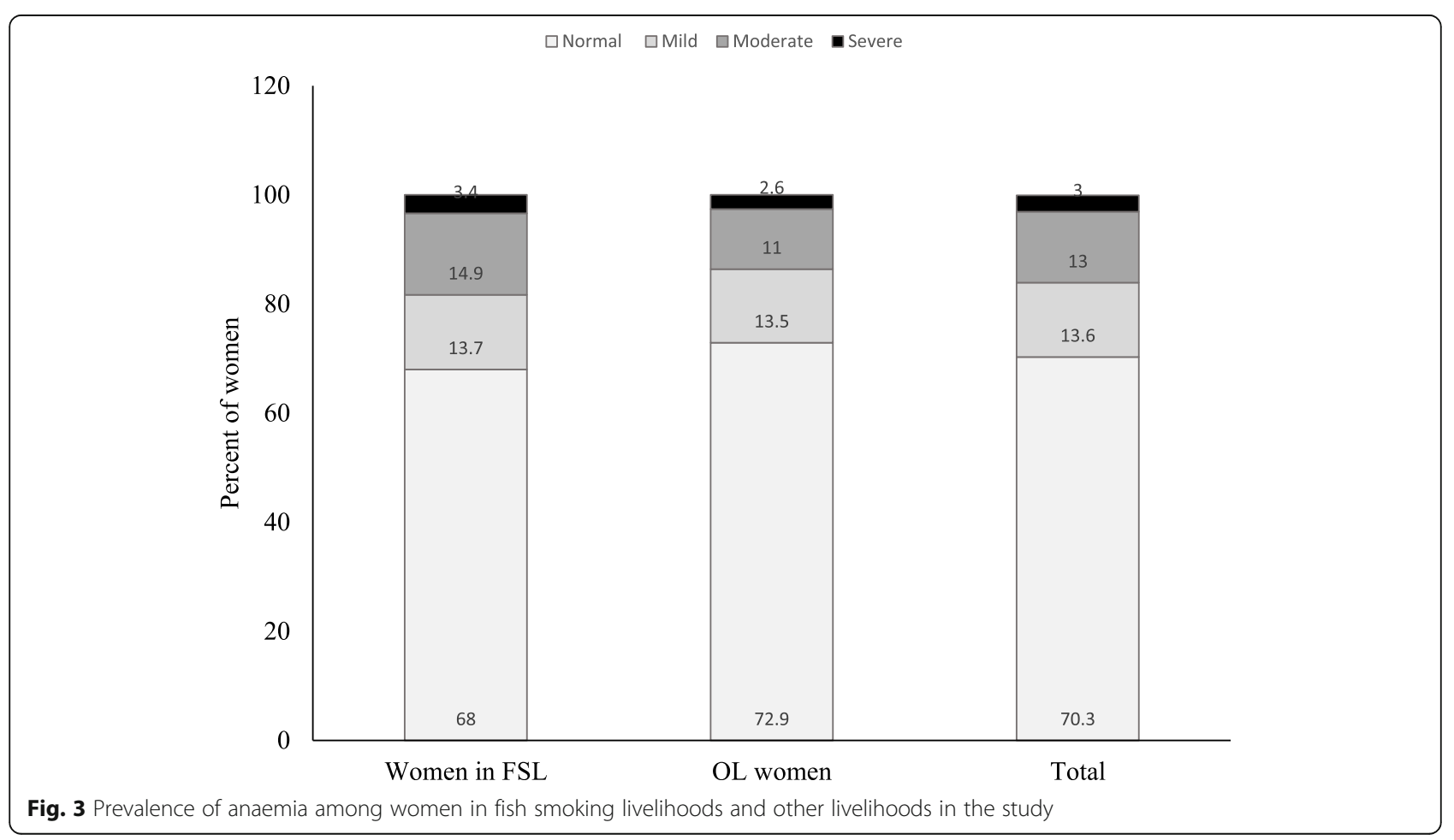


Table 4 Unadjusted and Adjusted differences in mean haemoglobin concentration between women in the study

\begin{tabular}{|c|c|c|c|c|}
\hline & FSL women ${ }^{a}(n=175)$ & $\begin{array}{l}\text { OL women }^{b} \\
(n=155)\end{array}$ & Difference in means $(95 \% \mathrm{Cl})^{c}$ & ${ }^{d}$ P-value \\
\hline \multicolumn{5}{|c|}{ Haemoglobin concentration $(\mathrm{g} / \mathrm{dL})$} \\
\hline Unadjusted & $12.3 \pm 1.9$ & $12.6 \pm 1.8$ & $-0.3(-0.7,0.1)$ & 0.17 \\
\hline Adjusted $^{e}$ & $12.2 \pm 0.2$ & $12.8 \pm 0.2$ & $-0.6(-1.2,-0.1)$ & 0.018 \\
\hline
\end{tabular}

${ }^{a}$ Women engaged in Fish smoking livelihood. ${ }^{b}$ Women engaged in other livelihoods unrelated to fish smoking ${ }^{c} 95 \% \mathrm{Cl}=95 \%$ Confidence Interval ${ }^{\mathrm{d}} \mathrm{P}$-values are based on general linear regression model (unadjusted) and ANCOVA (adjusted) for haemoglobin concentration ${ }^{\mathrm{e}}$ Adjusted for marital status, toilet facility, fever, fuel used for cooking, cigarette smoker in household, exposed to cigarette smoke outside the home at least once in past 12 months, number of days spent smoking fish in a week, and Animal Source Food (ASF) diversity in past 7-days

Peruvian children living in areas of Lima with higher outdoor concentrations of the biomass smoke pollutant particulate matter $\left(\mathrm{PM}_{2.5}\right)$ had lower mean haemoglobin concentrations and higher anaemia prevalence than those living in areas with lower concentrations of the pollutant [31]. Honda et al. [32] reported that $\mathrm{PM}_{2.5}$ was responsible for a $0.81 \mathrm{~g} / \mathrm{dL}$ decrease in average haemoglobin among old American adults [32].

Spending more days smoking fish was not associated with a higher risk of anaemia, though after controlling for covariates, a fish smoking livelihood was associated with a lower haemoglobin concentration and anaemia prevalence. Number of days of fish smoking may not necessarily reflect intensity of smoke exposure experienced by women as, depending on fish species and the type and stage of fish smoking, the number of actual hours spent near the smoking stove may differ widely [17]. Furthermore, there may have been limited variability in the women's fish smoking enterprises thus limiting differences in the types of fish being smoked and in

Table 5 Unadjusted and adjusted odds ratios for having anaemia among women in the study

\begin{tabular}{|c|c|c|c|c|}
\hline \multirow[t]{2}{*}{ Variable (referent) } & \multicolumn{2}{|l|}{ Unadjusted } & \multicolumn{2}{|l|}{ Adjusted } \\
\hline & Relative Risk $(95 \% \mathrm{Cl})^{\mathbf{b}}$ & ${ }^{\text {a P-value }}$ & Relative Risk $(95 \% \mathrm{Cl})^{\mathbf{b}}$ & ${ }^{\mathrm{a}} \mathrm{P}$-value \\
\hline \multicolumn{5}{|l|}{ Livelihood type } \\
\hline FSL $(O L)^{c}$ & $1.2(0.8,1.7)$ & 0.331 & $1.8(1.1,3.0)$ & 0.032 \\
\hline \multicolumn{5}{|l|}{ Age } \\
\hline$<35$ years ( $\geq 35$ years) & & & $1.3(0.9,2.0)$ & 0.17 \\
\hline \multicolumn{5}{|l|}{ Marital status } \\
\hline Married (Single) & & & $0.9(0.6,1.3)$ & 0.55 \\
\hline \multicolumn{5}{|l|}{ Ever been pregnant } \\
\hline Yes (No) & & & $0.8(0.4,1.3)$ & 0.33 \\
\hline \multicolumn{5}{|l|}{ Dewormed in past 3 mos } \\
\hline No (Yes) & & & $0.8(0.6,1.2)$ & 0.30 \\
\hline \multicolumn{5}{|l|}{ Fever in past 2 weeks } \\
\hline Yes (No) & & & $1.2(0.8,1.7)$ & 0.47 \\
\hline \multicolumn{5}{|c|}{ Household with toilet facility } \\
\hline No (Yes) & & & $0.7(0.5,1.1)$ & 0.09 \\
\hline \multicolumn{5}{|l|}{ Cooking fuel } \\
\hline Biomass fuel (other fuel) & & & $1.2(0.8,2.0)$ & 0.38 \\
\hline \multicolumn{5}{|c|}{ number of days spent smoking fish } \\
\hline More days (Fewer days) & & & $0.7(0.5,1.2)$ & 0.20 \\
\hline \multicolumn{5}{|l|}{ ASF diversity } \\
\hline Low (High) & & & $1.4(1.0,2.1)$ & 0.08 \\
\hline \multicolumn{5}{|l|}{$\%$ of iron from ASF } \\
\hline Low (High) & & & $1.2(0.9,1.7)$ & 0.22 \\
\hline
\end{tabular}

a P-value is based on logistic regression: Dependent variable = Anaemia (Present/Not Present)

${ }^{b} 95 \% \mathrm{Cl}=95 \%$ Confidence Interval ${ }^{\mathrm{C}}$ Fish smoking Livelihood (Other Livelihoods) 
smoking method. Alternatively, the lack of association between number of fish smoking days and anaemia may mean that the differences observed by livelihood type may not be due entirely to smoke exposure from smoking fish. Given the multiplicity of anaemia causes even within individuals, one risk factor such as smoke exposure is unlikely to explain the total burden of anaemia in an individual or population [33]. In addition to biomass smoke exposure being a potential cause of anaemia, anaemia may be caused by various factors associated with nutritional deficiencies, infection and infestations and genetic haemoglobin disorders [34]. Hence, being engaged in fish smoking as a primary livelihood may predispose women to other anaemia risk factors that were not measured in this study. The use of biomass fuel has been linked to certain infectious diseases such as tuberculosis that are also associated with increased risk of anaemia [13, 35].

Fish was the predominant ASF in the diets of both groups of women. This was expected as fish is the cheapest animal protein source across Ghana and contributes to more than $50 \%$ of total animal protein intake $[36,37]$. The two groups of women had similar 24-h total iron intakes from all sources and the contribution of iron from ASF was higher for the FSL women who had higher mean frequency of fish consumption in the past week. While the prevalence of consuming other ASF besides fish was higher for OL women, mean consumption frequency for iron-rich ASF such as livestock meats, organ meats, and poultry was low and not significantly different between the two groups. This suggests that fish was the main contributor to total iron intakes for both groups of women. This is plausible as the fish commonly available in the study community were the smaller fish species such as anchovy, sardinella, and herrings that tend to be richer sources of iron than the larger species because they are eaten whole with bones, head and viscera which have the highest concentration of iron and other micronutrients [19]. Cooking methods may also affect the iron content of animal protein sources. For example, Pourkhalili et al. [38] reported higher iron retention in grilled lamb meat compared to when the meat is boiled [38]. Total iron intake for both groups of women in the past day was just around $5 \mathrm{mg}$ which falls substantially short of the recommended daily intake of 19.6 for adult women assuming dietary iron bioavailability of $15 \%$. At even lower dietary bioavailability, levels expected for predominantly plant-based diets, the recommended daily intakes are even higher $(62 \mathrm{mg}$, $31 \mathrm{mg}$, and $25.8 \mathrm{mg}$ for 5,10 and $12 \%$ bioavailability, respectively) [39]. In addition to smoke exposure, nutritional iron inadequacy is probably an important contributor to anaemia in the study population. Coexistence of iron-deficiency anaemia and anaemia of inflammation from infections is reportedly common among developing country populations [40, 41]. Efforts to enhance the women's dietary diversity and consumption of iron-rich foods are also warranted in the community.

\section{Limitations}

Our study has some limitations. First the two groups of women were from the same community where fish smoking is the dominant livelihood for women so that we did not have a true 'unexposed' group because: 1) more than $50 \%$ of women classified as being in primary livelihoods unrelated to fish smoking occasionally assisted with smoking activities of families and friends; and, 2) fish smoking was generally an outdoor activity indicating community-wide exposure to smoke. This may have underestimated the effect observed. Further, smoke exposure was not directly measured and so we cannot be truly certain whether the association observed was due to smoke exposure per se or other unmeasured characteristics that the women had. Iron intake was based on one 24-h recall which may not necessarily reflect usual intakes among the participants.

\section{Conclusion}

The adverse effects of biomass smoke exposure on morbidity and mortality associated with respiratory and cardiovascular conditions and cancers in developing country populations has been long recognized, however the association with anaemia has received less attention. Our study suggests that women who smoke fish as their primary livelihood may have additional risks of anaemia besides those posed by other well recognized contributors to anaemia such as poor diet, and infections. This added risk may be especially important for reducing population-level anaemia risk given how ubiquitous fish smoking activities are across Ghana and throughout many communities in West Africa as described previously. The study also showed that the women's iron intake in the past 24-h was well below the required iron intake with probability the women had underlying iron deficiency. Therefore, efforts to reduce smoke emissions from fish smoking ovens and to enhance dietary iron intake may be warranted in efforts to address different causes of anaemia in our study community and beyond given the potential for impact at scale. Further research is needed to understand the mechanisms of the association and to determine causality.

\section{Abbreviations}

ASF: Animal Source Food; FAO: Food and Agriculture Organization; FSL: Fish Smoking Livelihood; OL: Other Livelihood PM:Particulate Matter; WHO: World Health Organization; WRA: Women of Reproductive Age 


\section{Supplementary Information}

The online version contains supplementary material available at https://doi. org/10.1186/s40795-021-00456-w.

Additional file 1. Questionnaire on the risk of anaemia among women engaged in biomass-based fish smoking as their primary livelihood in the Central Region of Ghana. The word file contains the questionnaire used to gather information on the personal social demographic characteristics, reproductive history, health and use of firewood of the study participants and another section showing the modified food frequency questionnaire.

\section{Acknowledgements}

We appreciate the contributions of Claudia Ewa, Griffith Ammah, Princess Abakah and Eric Arthur to the completion of this study and publication. We are also grateful to all the women who took part in the study.

\section{Authors' contributions}

DAA, EKC, SAA and AKC designed the research questionnaire. DAA conducted the data collection. EKC, SAA, DAA and AKC wrote the methods section. DAA, SAA and AKC performed statistical analysis. EKC and DAA discussed the results. EKC, DAA, SAA, AKC and ADJ critically reviewed and edited the manuscript. All authors read and approved the final manuscript.

\section{Funding}

This research was supported with a grant from the Bill \& Melinda Gates Foundation (OPP1182940). The funders did not participate in the design of the study, data collection, analysis nor interpretation of data in the writing of this manuscript. All the information and opinions expressed in the manuscripts are based solely on the authors' research and interpretation of the research.

\section{Availability of data and materials}

The datasets used or analysed during the current study are available from the corresponding author on reasonable request.

\section{Declarations}

\section{Ethics approval and consent to participate}

Ethical approval for the study was obtained from the Ethics Committee for the College of Basic and Applied Science (ECBAS) of the University of Ghana (approval reference: ECBAS 003/18-19). The study was explained to all eligible participants at the time of recruitment and each participant signed or if illiterate, thumb-printed an informed consent document before being enrolled in the study.

\section{Consent for publication}

Not applicable.

\section{Competing interests}

The authors declare that they have no competing interests.

\section{Author details}

'Department of Nutrition and Food Science, University of Ghana, P.O. Box LG 134, Accra, Ghana. ${ }^{2}$ Regional Institute for Population Studies, University of Ghana, P.O. Box LG 96, Accra, Ghana. ${ }^{3}$ School of Public Health, University of Michigan, Ann Arbor, Ml 48109-2029, USA.

Received: 26 August 2020 Accepted: 7 July 2021

Published online: 06 September 2021

\section{References}

1. GDHS. Ghana demographic health survey [Internet]. [GSS, GHS, AND ICF INTERNATIONAL]. 2014 [cited 2019 Apr 8]. Available from: https://dhsprogra m.com/pubs/pdf/FR307/FR307.pdf.

2. CDC. Hemoglobinopathies current practices for screening, confirmation and follow up [Internet]. 2015 [cited 2019 Jun 7]. Available from: https://www.cdc. gov/ncbddd/sicklecell/documents/nbs_hemoglobinopathy-testing_122015.pdf.

3. Kassebaum NJ, Jasrasaria R, Naghavi M, Wulf SK, Johns N, Lozano R, et al. RED CELLS, IRON, AND ERYTHROPOIESIS A systematic analysis of global anemia burden from 1990 to 2010. Blood. 2014;123(5):615-25. https://doi. org/10.1182/blood-2013-06-508325.

4. WHO. The global prevalence of anaemia in 2011. WHO Rep [Internet]. 2015; 48 [cited 2020 Feb 26]. Available from: http://apps.who.int/iris/bitstream/1 0665/177094/1/9789241564960_eng.pdf?ua=1.

5. Petry N, Olofin I, Hurrell RF, Boy E, Wirth JP, Moursi M, et al. The proportion of anemia associated with iron deficiency in low, medium, and high human development index countries: a systematic analysis of national surveys. Nutrients. 2016:8(11):1-17.

6. Bissinger R, Bhuyan M, Qadri SM, Lang F. Oxidative stress, eryptosis and anemia : a pivotal mechanistic nexus in systemic diseases. FEBS J 2019; 286(5):826-854, https://doi.org/10.1111/febs.14606.

7. Naeher LP, Brauer M, Lipsett M, Zelikoff JT, Simpson CD, Koenig JQ, et al. Woodsmoke health effects: a review. Inhal Toxicol. 2007;19(1):67-106. https://doi.org/10.1080/08958370600985875.

8. Padhy P, Padhi B. Effects of biomass combustion smoke on hemotological and antioxidant provile among children (8-13 years) in India. Inhal Toxicol. 2009;21(8):705-11. https://doi.org/10.1080/08958370802448961.

9. Weiss G, Goodnough LT. Anemia of chronic disease. N Engl J Med. 2005; 352(10):1011-23. https://doi.org/10.1056/NEJMra041809.

10. Kyu HH, Georgiades K, Boyle MH. Biofuel smoke and child Anemia in 29 developing countries: a multilevel analysis. Ann Epidemiol. 2010;20(11):8117. https://doi.org/10.1016/j.annepidem.2010.07.096.

11. Mishra $V$, Retherford R. Does biofuel smoke contribute to anemia and stunting in early childhood. Int J Epidemiol. 2006;36(1):1-33.

12. Machisa M, Wichmann J, Nyasulu PS. Biomass fuel use for household cooking in Swaziland: is there an association with anaemia and stunting in children aged 6-36 months? Trans R Soc Trop Med Hyg. 2013;107(9):535-44. https://doi.org/10.1093/trstmh/trt055.

13. Page CM, Patel A, Hibberd PL. Does smoke from biomass fuel contribute to Anemia in pregnant women in Nagpur, India? A cross-sectional study. PLoS One. 2015;10(5):1-13.

14. Sukhsohale N, Narlawar U, Phatak M. Indoor air pollution from biomass combustion and its adverse health effects in Central India: an exposureresponse study. Indian J Community Med Off Publ Indian Assoc Prev Soc Med. 2013;38(3):162-7.

15. Neufeld LM, Haas JD, Ruel MT, Grajeda R, Naeher LP. Smoky indoor cooking fires are associated with elevated hemoglobin concentration in irondeficient women. Pan Am J Public Heal [Internet]. 2004;15(2):110-8. Available from: http://www.scielosp.org/pdf/rpsp/v15n2/20820.pdf. https:// doi.org/10.1590/S1020-49892004000200006.

16. FAO. Fishery and aquaculture country profiles (Ghana). [Internet]. FAO Fisheries and Aquaculture Department. 2016 [cited 2019 Jun 26]. Available from: http://www.fao.org/fishery/facp/NGA/en.

17. Sakyi M, Jia C, Ampofo-Yeboah A, Aglago A. Fish smoking in Ghana: a review. J Fish Sci. 2019;13(3):13-24.

18. Dadzie EK, Ephraim RKD, Afrifa J, Quaicoe R, Bediako BS, Duku Bl, et al. Persistent exposure to wood smoke is associated with variations in biochemical and hematological indices among regular wood burners in the Cape Coast metropolis, Ghana. Sci African. 2019;4:e00100. https://doi.org/1 0.1016/j.sciaf.2019.e00100.

19. Kawarazuka N, Bene C. The potential role of small fish species in improving micronutrient deficiencies in developing countries : building evidence. Public Health Nutr. 2011;14(11):1927-38. https://doi.org/10.1017/S13 68980011000814

20. Ghana Statistical Service. 2010 Population and housing census. Ghana Stat Serv [Internet]. 2012;1-117 [cited 2018 Sep 12]. Available from: http://www.statsgha na.gov.gh/docfiles/2010phc/Census2010_Summary_report_of_final_results.pdf.

21. Invisible Fishers. The invisible fishers - full text view - ClinicalTrials.gov [Internet]. 2018 [cited 2020 Jun 12]. Available from: https://clinicaltrials.gov/ ct2/show/study/NCT03498755.

22. WHO. Worldwide prevalence of anaemia, WHO Vitamin and Mineral Nutrition Information System, 1993-2005. Public Heal Nutr. 2009;12(4):44454 Available from: http://whqlibdoc.who.int/publications/2008/9789241 596657_eng.pdf.

23. FAO. Dietary assessment: a resource guide to method selection and application in low resource settings [Internet]. 2018 [cited 2020 Jul 9]. p. 152. Available from: http://www.fao.org/3/i9940en/l9940EN.pdf.

24. FAO. Minimum dietary diversity for women a guide to measurement [Internet]. 2016 [cited 2019 Jun 26]. Available from: http://www.fao.org/3/ai5486e.pdf. 
25. Tseng M, Chakraborty H, Robinson DT, Mendez M, Kohlmeier L. Adjustment of iron intake for dietary enhancers and inhibitors in population studies : bioavailable iron in rural and urban residing Russian women and children. J Nutr. 1997;127(8):1456-68.

26. De Freitas JS, Costa PS, Costa LR, Naghettini AV. Evaluation of clinical and laboratory variables associated with anemia in pediatric patients on hemodialysis. J Pediatr (Rio J). 2015;91(1):87-92. https://doi.org/10.1016/j. jped.2014.05.009

27. Mickey RM, Greenland S. The impact of confounder selection criteria on effect estimation. Am J Epidemiol. 1989;129(1):125-37. https://doi.org/10.1 093/oxfordjournals.aje.a115101.

28. Accinelli RA, Leon-Abarca JA. Solid fuel use is associated with anemia in children. Environ Res. 2017;158(January):431-5 Available from: http://www. ncbi.nlm.nih.gov/pubmed/28689034.

29. Bishwajit G, Yaya S, Tang S, Hossain A, Fan Y, Akter M, et al. Association of Living Arrangement Conditions and Socioeconomic Differentials with Anemia status among women in rural Bangladesh. Biomed Res Int. 2016; 2016:1-6. https://doi.org/10.1155/2016/4571686.

30. Dutta A, Ray M, Banerjee A. Systemic inflammatory changes and increased oxidative stress in rural Indian women cooking with biomass fuels. Toxicol Appl Pharmacol. 2012;261(3):255-62. https://doi.org/10.1016/j.taap.2012.04. 004.

31. Morales-ancajima VC, Tapia V, Vu BN, Liu Y, Alarc DE, Gonzales GF. Increased outdoor PM 2.5 concentration is associated with moderate / severe anemia in children aged 6-59 months in Lima, Peru. Journal environmental and public health. 2019;2019.

32. Honda T, Pun V, Manjourides J, Helen S. Anemia prevalence and hemoglobin levels are associated with long-term exposure to air pollution in an older population. Environ Int. 2017;101(2):125-32 Available from: http://www.embase.com/search/results? subaction=viewrecord\&from= export\&id=L614272295\%OAhttp://dx.doi.org/10.1016/j.envint.2017.01.017.

33. Chaparro CM, Suchdev PS. Anemia epidemiology, pathophysiology, and etiology in low- and middle-income countries. Ann N Y Acad Sci. 2019; 1450(1):15-31. https://doi.org/10.1111/nyas.14092.

34. Balarajan Y, Ramakrishnan U, Özaltin E, Shankar AH, Subramanian SV. Anaemia in low-income and middle-income countries. Lancet. 2011; 378(9809):2123-35. https://doi.org/10.1016/S0140-6736(10)62304-5.

35. Gil-Santana L, Cruz LAB, Arriaga MB, Miranda PFC, Fukutani KF, SilveiraMattos PS, et al. Tuberculosis-associated anemia is linked to a distinct inflammatory profile that persists after initiation of antitubercular therapy. Sci Rep. 2019;9(1):1-8.

36. FAO. The state of world fisheries and aquaculture. Meeting the sustainable development goals. [Internet]. Rome; 2018 [cited 2019 May 28]. p. 210. Available from: http://www.fao.org/3/i9540en/19540EN.pdf.

37. GAIN. Ghana fish and seafood report. Global Agricultural Information Network [internet]. 2019;1-15 [cited 2020 May 28]. Available from: http://a griexchange.apeda.gov.in/MarketReport/Reports/Fish_and_Seafood_ Report_Accra_Ghana_3-8-2019.pdf.

38. Pourkhalili A, Mirlohi M, Rahimi E. Heme iron content in lamb meat is differentially altered upon boiling, grilling, or frying as assessed by four distinct analytical methods. Sci World J. 2013;2013:1-5. https://doi.org/10.11 55/2013/374030.

39. WHO. Vitamin and mineral requirements in human nutrition second edition. [Internet]. 2nd edition. World Health Organization, 2004 [cited 2020 May 28] p 342. Aailable from: https://apps.who.int/iris/rest/bitstreams/50670/retrieve.

40. Ganz T. Anemia of inflammation. N Engl J Med. 2019;381(12):1148-57. https://doi.org/10.1056/NEJMra1804281.

41. Shaw JG, Friedman JF. Iron deficiency Anemia : focus on infectious diseases in lesser developed countries. Hindawi Publ Corp. 2011;2011:1-6.

\section{Publisher's Note}

Springer Nature remains neutral with regard to jurisdictional claims in published maps and institutional affiliations.

Ready to submit your research? Choose BMC and benefit from:

- fast, convenient online submission

- thorough peer review by experienced researchers in your field

- rapid publication on acceptance

- support for research data, including large and complex data types

- gold Open Access which fosters wider collaboration and increased citations

- maximum visibility for your research: over $100 \mathrm{M}$ website views per year

At BMC, research is always in progress.

Learn more biomedcentral.com/submissions 